\title{
ESTIMATION OF SOIL LOSSES BY THE IMPROVED TILLAGE HOMOGENIZATION MODEL AND RUSLE MODEL
}

\author{
S. Bouhlassa, N. Bouhsane* \\ Laboratory of Radiochemistry and Nuclear Chemistry, Department of Chemistry, Mohammed V University, Faculty of Science \\ Rabat-4 Avenue Ibn Battouta, BP 1014 RP, Rabat, Morocco \\ naimabouhsane@gmail.com (N. Bouhsane), sbouhlassa1951@gmail.com (S. Bouhlassa)
}

Commission III, WG III/10

KEY WORDS: Erosion, Magnetic Susceptibility, Improved Tillage Homogenization Model (T-H), RUSLE, GIS

\begin{abstract}
:
Soil erosion by water is a major environmental problem in the Mediterranean areas. It results in land degradation and soil losses, decreases soil structural stability, and increases soil erodibility. Hence, the need for reliable scientific methods for obtaining soil erosion data becomes crucial. The study aims to estimate soil loss in the Moroccan watershed using two soil erosion estimation models and to discuss the differences between those models. The first model used in this study is the improved tillage homogenization model (T-H) which permits to predict the magnetic susceptibility values after erosion, the second one is the empirical model based on the Revised Universal Soil Loss Equation RUSLE. The results showed that: i) higher soil losses using tillage homogenization (T-H) model have occurred in the upper and lower slopes in the cultivated transect, and in the middles lopes and lower slopes in the forested transect; ii) the average of annual soil loss obtained by RUSLE model is about $20.21 \mathrm{t} / \mathrm{ha} / \mathrm{yr}$; iii) $\mathrm{T}$ $\mathrm{H}$ model allows us to estimate the total cumulative soil erosion during the past and, while RUSLE model is designed for predicting annual soil loss resulting from sheet erosion under given conditions.
\end{abstract}

\section{INTRODUCTION}

Soil erosion is a major problem in many regions in Morocco. It contributes to soil degradation and the loss of a higher amount of soil. Agricultural practices such as tillage operations are considered the major sources of soil erosion and degradation (Jordanova et al., 2011). Several erosion techniques and models have been established and proposed to evaluate soil erosion. Radionuclide tracer method such as ${ }^{137} \mathrm{Cs}$ has been used to estimate the soil redistribution in the filed caused by erosion and deposition (Hassouni and Bouhlassa., 2006; Ayoubi et al., 2012; Zhang et al., 2015). However, this method is costly for large areas and needs a long evaluation period. On the other hand, the ${ }^{137} \mathrm{Cs}$ method allows us to estimate the cumulative erosion only for the last 50 years and cannot give a longer-term estimate of soil loss rates (Royall, 2004; Jordanova et al., 2011). Empirical models such as RUSLE (Revised Universal Soil Loss Equation) based on GIS (Geographic Information System) data have been used largely (Renard et al., 1997; Wijesundara et al., 2018); but it depends on numerous input parameters that are not available at all spatial and temporal scales, and leads often to underestimated or overestimated results (Royall, 2004). Compared with radionuclide methods, the magnetic susceptibility technique has been proven to be the fast and non-destructive method to estimate soil erosion (Sadiki et al., 2009; Bouhlassa and Bouhsane, 2019; Liu et al., 2015; Yu et al., 2017; 2019). The study carried by Bouhlassa and Bouhsane (2019) establishes a methodology and specifies conditions that improves the use of magnetic susceptibility in the estimation of erosion or redeposition in the watershed. Tillage homogenization $(\mathrm{T}-\mathrm{H})$ model based on magnetic susceptibility parameter has been proposed by Royall (2001) to estimate soil loss in cultivated lands. The model establishes the magnetic susceptibility variation when an initially uncultivated soil is seasonally ploughed and eroded (Jordanova et al., 2014). This model permits to estimate cumulative soil loss at a point based on easily, cheaply, and rapidly acquired measurement of the top soil magnetism (Royall , 2004). T-H model was used by several researchers, such as Jordanova et al (2014) and Bouhlassa and Bouhsane (2019).

The objective of this study is to evaluate soil erosion using two erosion models in the Mezguida watershed, then compare these two models.

\section{MATERIALS AND METHODS}

\subsection{Study area description}

The Mezguida catchment is located in the North of Morocco at $33^{\circ} 4^{\prime} 48^{\prime \prime}-32^{\circ} 55^{\prime} 12^{\prime \prime} \mathrm{N}$ and $6^{\circ} 28^{\prime} 12^{\prime \prime}-6^{\circ} 13^{\prime} 12^{\prime \prime} \mathrm{W}$; it is situated in less than 5 kilometers from the north-west of the city of Boujaad, on the road to Tlat - Chougrane in the Qasba Tadla region. It constitutes one of the subcatchments of the Bouregreg basin located near to Rabat (Figure 1). Its area is approximately $240 \mathrm{~km}^{2}$. The Mezguida catchment is characterized by a Mediterranean climate and by annual precipitations about of $379 \mathrm{~mm}$. Its lithology is dominated by schist, marl, limestone and minor composition of red argil in some location. The Mezguida watershed has diverse land uses dominated by cultivated lands; forested lands, pure green oak, and matorrals occupy a small areas in the catchment. The major part of the watershed is characterized by a slope classes which are between $0^{\circ}$ and $32^{\circ}$, while a small area in the watershed has a slope degree exceeding $40^{\circ}$. The soil types

\footnotetext{
* Corresponding author
} 
present in the Mezguida watershed are the Chromic Luvisol and Calcic Cambisols (Clark, 2015).

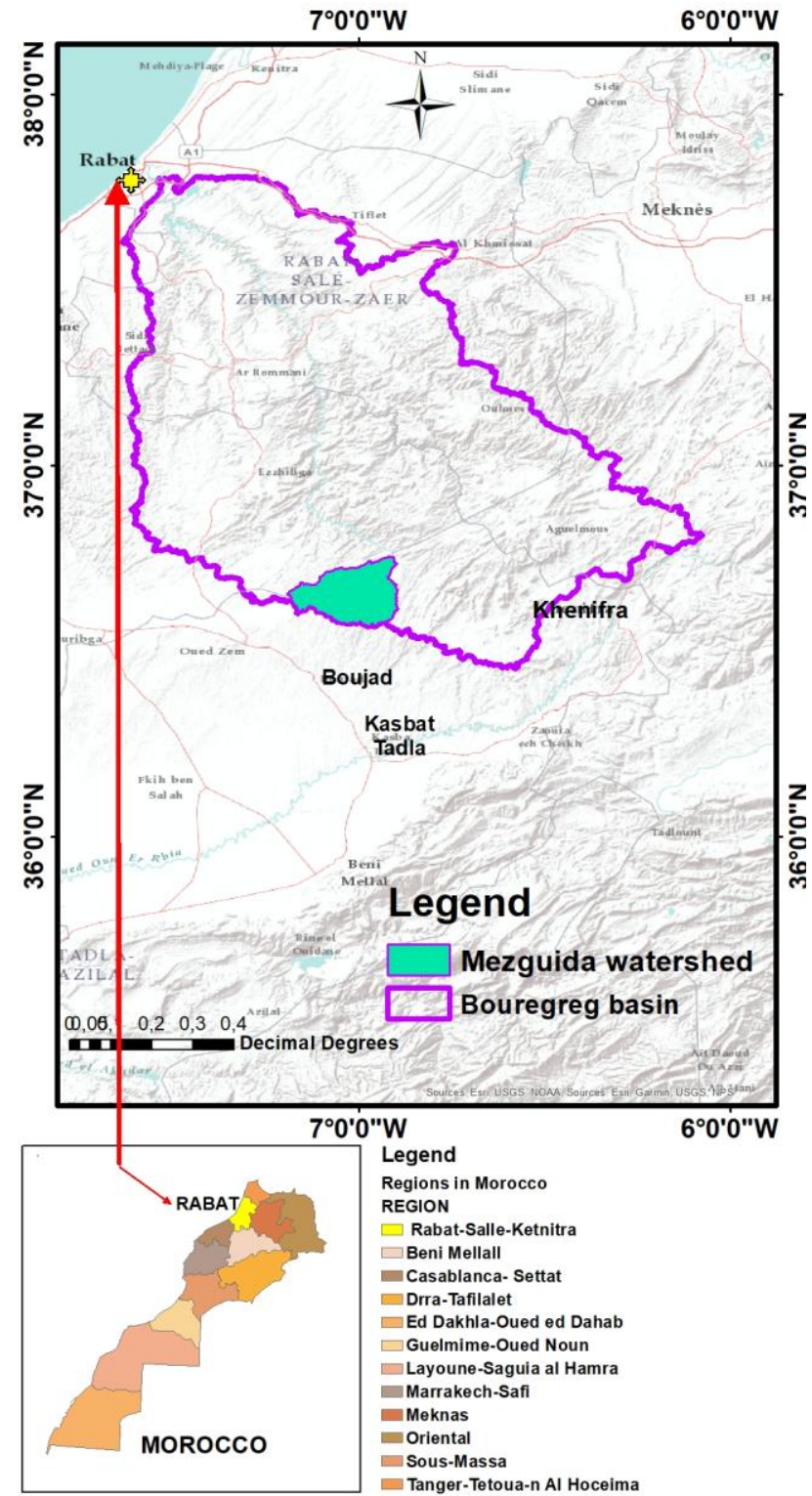

Figure 1. Study area location

\subsection{Soil sampling and magnetic measurements}

Several soil cores were sampled along cultivated (MZ13) and forested (MZ17) transects in five slope positions including summit (SU), shoulder (SH), backslope (BS), footslope (FS), and toeslope (TS). The characteristics of the two transects and soil samples are given in the table 1 . Cores samples witch may reach $35 \mathrm{~cm}$ in length depending on soil depth were collected using a hand auger of $6 \mathrm{~cm}$ in diameter and $50 \mathrm{~cm}$ in length. These cores were divided into samples with layers of $5 \mathrm{~cm}$ to measure the magnetic susceptibility vertically, and then conserved in a plastic bags. We have 109 soil samples collected in the total at the 30 sampling sites. Each sample was oven-dried at $40{ }^{\circ} \mathrm{C}$ for eight hours and then sieved by a $1 \mathrm{~mm}$ plastic sieve. Each sample is recovered in $10 \mathrm{~cm}^{3}$ cylindrical boxes and submitted to magnetic susceptibility measurements using a Bartington magnetic susceptibility meter (MS2) and a dual frequency sensor (MS2B) (Bartington, 2001). Magnetic susceptibility may be either expressed per unit volume (volume-specific susceptibility, $\kappa$ ) or per unit mass (massspecific susceptibility, $\chi$ ). The volume- specific magnetic susceptibility $(\kappa)$ was measured at low $\left(0.47 \mathrm{kHz} ; \kappa_{\mathrm{lf}}\right)$ and high frequency $\left(4.7 \mathrm{kHz} ; \kappa_{\mathrm{hf}}\right)$ (Dearing, 1999). Soil bulk density $(\rho)$ was calculated by dividing the dried soil mass by the volume. Mass-specific low-frequency magnetic susceptibility $\left(\chi_{\mathrm{lf}}\right)$ is expressed in unit of $10^{-8} \mathrm{~m}^{3} \mathrm{~kg}^{-1}$ and defined by the following equation (1):

$$
\chi_{\mathrm{lf}}=\kappa_{\mathrm{lf}} / \rho
$$

Table 1. Slope position of different cores selected in the MZ17 and MZ13 transect

\begin{tabular}{|c|c|c|c|c|}
\hline $\begin{array}{c}\text { Slope } \\
\text { position }\end{array}$ & $\begin{array}{c}\text { Slope } \\
\left({ }^{\circ}\right) \text { in } \\
\text { cultivated } \\
\text { transect } \\
(\text { MZ13) }\end{array}$ & $\begin{array}{c}\text { Cores in } \\
\text { MZ13 } \\
\text { transect }\end{array}$ & $\begin{array}{c}\text { Slope } \\
\left({ }^{\circ}\right) \text { in } \\
\text { forested } \\
\text { transect } \\
(M Z 17)\end{array}$ & $\begin{array}{c}\text { Cores in } \\
\text { MZ17 } \\
\text { transect }\end{array}$ \\
\hline Summit & 5 & $13 \mathrm{~A}$ & 45 & 17B \\
\hline Shoulder & 20 & 13B & 20 & $17 \mathrm{C}$ \\
\hline Backslope & $10-30$ & $\begin{array}{c}13 \mathrm{C} ; 13 \mathrm{D} \\
13 \mathrm{E} ; 13 \mathrm{~F} ; \\
13 \mathrm{G} ; 13 \mathrm{H} \\
; 13 \mathrm{I} ; 13 \mathrm{~J} ; \\
13 \mathrm{~K}\end{array}$ & 20 & $\begin{array}{c}17 \mathrm{D}, 17 \mathrm{E} \\
17 \mathrm{~F}, 17 \mathrm{G} \\
17 \mathrm{H} ; 17 \mathrm{I} \\
17 \mathrm{~J} ; 17 \mathrm{~K} ; \\
17 \mathrm{~L}\end{array}$ \\
\hline Footslope & 35 & $13 \mathrm{~L}$ & 8 & $\begin{array}{l}17 \mathrm{M} \\
17 \mathrm{~N}\end{array}$ \\
\hline Toeslope & 5 & $13 \mathrm{M}$ & 5 & $\begin{array}{c}\text { 17P; } 17 \mathrm{P} \\
17 \mathrm{Q}\end{array}$ \\
\hline
\end{tabular}

\subsection{Soil erosion models used in the Mezguida watershed} 2.3.1. Tillage homogenization (T-H) model (Royall, 2001; Bouhlassa and Bouhsane, 2019)

Tillage homogenization model is a methodology proposed by Royall (2001) and improved by Bouhlassa and Bouhsane (2019) for estimating erosion depth using magnetic susceptibility of soils. This model allows predicting the mean values of magnetic parameters of the ploughing layers after erosion of the surface soil layer (Bouhlassa and Bouhsane, 2019). To run this model, a reference profile of unperturbed and non-eroded soil is mandatory (Royall, 2004; Landgraf and Royall, 2006; Jordanova et al., 2014). The T-H model is based on the supposition that tillage operations cause homogenization of the uppermost $20 \mathrm{~cm}$, and therefore magnetic signal should be uniform within this layer (Jordanova et al, 2014; Bouhlassa and Bouhsane, 2019). After an erosion process, a deeper soil layer are involved in ploughed horizon with a decrease of the initial value of magnetic susceptibility. According to Royall (2001), the T-H model is expressed by the mathematical equations (2 et 3) (Bouhlassa and Bouhsane, 2019):

Where,

$$
\mathrm{X}_{0}=\left(\Sigma \chi_{\mathrm{i}}\right) / \mathrm{N}
$$

$\chi_{i}=$ the magnetic susceptibility of the soil layer $\mathrm{i}$

$\mathrm{N}=$ the number of the layers in plough depth or $\mathrm{A}_{\mathrm{p}}$ horizon $\mathrm{X}_{0}=$ the average value of soil susceptibility without soil loss

Where, 
$\mathrm{X}_{1}=$ the predicted magnetic susceptibility of Ap horizon after soil loss of the first layer

$\mathrm{X}_{\mathrm{N}+1}=\mathrm{X}$ value of the first soil layer below the plough depth.

The above calculations lead to the construction of predictive curve linking magnetic susceptibility associated to surface soil losses or erosion depth. In our approach we use a single increment of $5 \mathrm{~cm}$ in order to conform to the sampling interval of $5 \mathrm{~cm}$ along the soil profile (Bouhlassa and Bouhsane, 2019).

\subsubsection{RUSLE model}

The Revised Universal Soil Loss Equation model is a multiplicative function of five factors that control water erosion. The soil loss is calculated by the following equation (4) (Wischmeier and smith, 1978; Renard et al., 1991):

$$
\mathrm{A}=\mathrm{K}^{*} \mathrm{R}^{*} \mathrm{LS} * \mathrm{C}^{*} \mathrm{P}
$$

where,

$\mathrm{A}=$ the average annual soil loss per unit area $\left(\mathrm{t} \mathrm{ha}^{-1} \mathrm{year}^{-1}\right)$ $\mathrm{R}=$ the rainfall-runoff erosivity factor $\left(\mathrm{MJ} \mathrm{mm} \mathrm{ha}{ }^{-1} \mathrm{~h}^{-1} \mathrm{year}^{-1}\right)$ $\mathrm{K}=$ the soil erodibility factor ( $\mathrm{t}$ ha h $\mathrm{MJ}^{-1} \mathrm{ha}^{-1} \mathrm{~mm}^{-1}$ ) $\mathrm{LS}=$ the topographic factor (dimensionless) which includes slope length factor (L) and slope steepness factor (S)

$\mathrm{C}=$ the cover and management factor

$\mathrm{P}=$ the support and conservation practices factor

The RUSLE model, ArcGIS 10.3.1 (2015), Microsoft Office Excel 2007, and different equations proposed by many authors were used to undertake the data analysis. The LS factor map is derived from DEM (Digital Elevation Model) and the application of the equation of LS factor proposed by Mitasova et al (1996) in ArcGIS. Each RUSLE factor with associated attribute data is digitally encoded in a GIS database to obtain five thematic maps; and finally the application of RUSLE model to the resultant maps allows obtaining the soil erosion map. The diagram given in figure 2 shows the methodology applied to achieve the intended objectives.

Erosion factors in this study are estimated using data obtained from Hydraulic Basin Agency of Bouregreg and Chaouia of Benslimane- Morocco (ABHBC), SIGMED (2015) project and the public website of the United States Geological Survey's Earth Explorer (USGS).

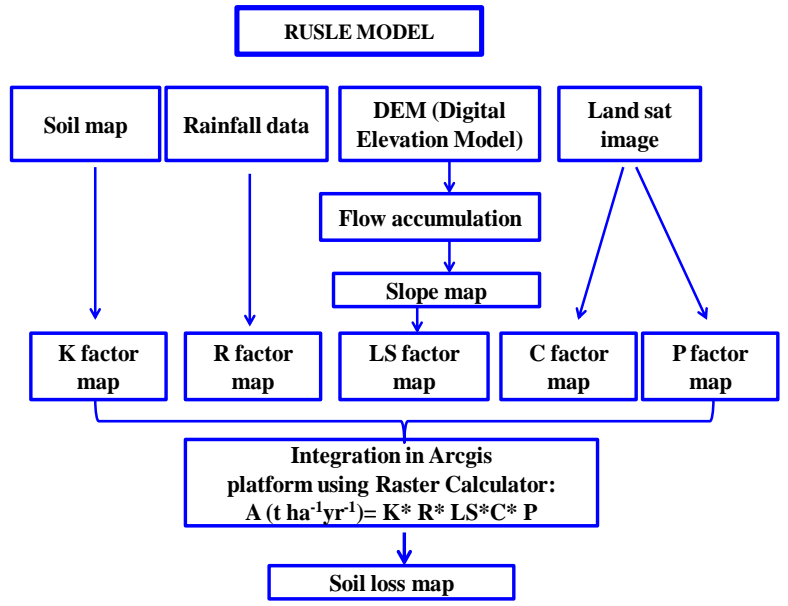

Figure 2. Diagram of the Soil loss analysis by RUSLE model

\section{RESULTS AND DISCUSSION}

\subsection{Estimation of soil erosion by improved tillage homogenization ( $\mathrm{T}-\mathrm{H})$ model}

The application of tillage homogenization model (T-H) proposed by Royall (2001) as improved by Bouhlassa and Bouhsane (2019) requires a reference profile supposed undisturbed in recent decades. In our case the core 17A which is located in the top of the MZ17 transect sampled in the forest area is chosen as a reference, it is extended to a depth of 165 $\mathrm{cm}$ to reach the basic material (Figure 3 ).

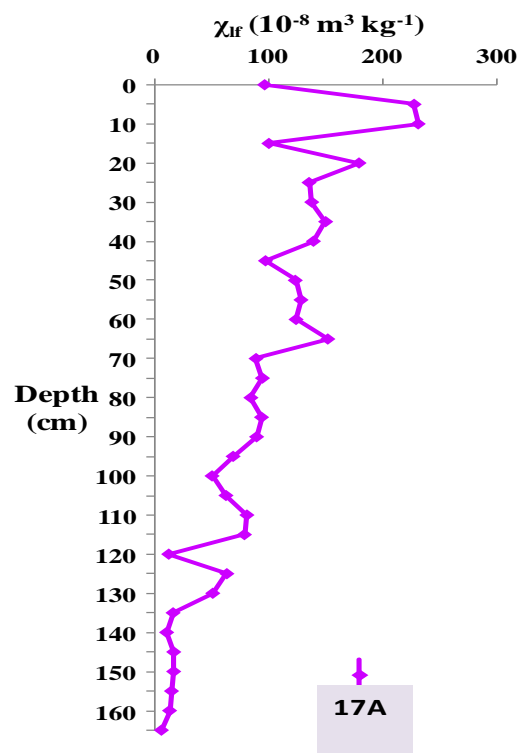

Figure 3. Depth distribution of magnetic susceptibility $\chi_{\mathrm{If}}$ in the reference core site (17A)

The (T-H) model conducted to a predictive curve given in figure 4. This figure is a polynomial curve which reproduces the dependence of $\chi_{\mathrm{lf}}$ on soil loss depth for soils (having the same lithology and condition climatic of the reference) related to the reference site.

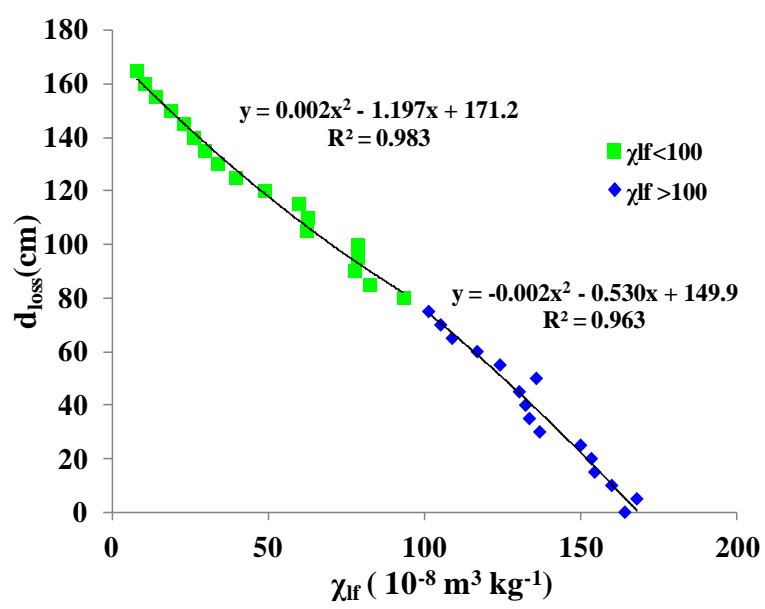

Figure 4. Predictive curve obtained by T-H model showing the polynomial relations correlating the soil loss (in $\mathrm{cm}$ ) to measured $\chi_{\mathrm{lf}}$ in reference soil after tillage homogenization $(\mathrm{T}$ $\mathrm{H}$ model) 
Using the figure 4, we obtained the eroded soil estimates in $\mathrm{cm}$ in each soil core and at each slope position along the MZ17 and MZ13 transects (tables 2 and 3).

Table 2. Soil loss in different soil profiles after homogenization (in $\mathrm{cm}$ ) in MZ17 transect

\begin{tabular}{cccc}
\hline $\begin{array}{c}\text { Slope } \\
\text { position of } \\
\text { cores in } \\
\text { MZ17 } \\
\text { transect }\end{array}$ & $\begin{array}{c}\text { Cores in } \\
\text { MZ17 } \\
\text { transect }\end{array}$ & $\begin{array}{c}\text { Mean } \boldsymbol{\chi}_{\text {If }} \\
\mathbf{( 1 0}^{-8} \mathbf{m}^{\mathbf{3}} \\
\mathbf{k g}^{-1} \mathbf{)}\end{array}$ & $\begin{array}{c}\text { Erosion by } \\
\mathbf{T H} \text { model } \\
\mathbf{d}_{\text {loss }}(\mathbf{c m})\end{array}$ \\
\hline Summit & $17 \mathrm{~B}$ & 89.58 & -80.021 \\
\hline Shoulder & $17 \mathrm{C}$ & 21.4 & -146.49 \\
\hline Backlsope & $17 \mathrm{D}$ & 27.45 & -139.84 \\
& $17 \mathrm{E}$ & 80.46 & -87.83 \\
& $17 \mathrm{~F}$ & 62.31 & -104.38 \\
& $17 \mathrm{G}$ & 140.5 & -35.95 \\
& $17 \mathrm{H}$ & 125.16 & -52.22 \\
& $17 \mathrm{I}$ & 35.63 & -131.08 \\
& $17 \mathrm{~J}$ & 75.89 & -91.87 \\
& $17 \mathrm{~K}$ & 43.58 & -122.83 \\
& $17 \mathrm{~L}$ & 13.86 & -154.99 \\
\hline Footslope & $17 \mathrm{M}$ & 124.19 & -53.23 \\
& $17 \mathrm{~N}$ & 58.98 & -107.55 \\
\hline Toeslope & $17 \mathrm{O}$ & 31.99 & -134.95 \\
& $17 \mathrm{P}$ & 15.91 & -152.66 \\
& $17 \mathrm{Q}$ & 54.42 & -111.98 \\
\hline
\end{tabular}

Table 3. Soil loss in different soil profiles after homogenization (in $\mathrm{cm}$ ) in MZ13 transect

\begin{tabular}{cccc}
\hline $\begin{array}{c}\text { Slope } \\
\text { position in } \\
\text { MZ13 } \\
\text { transect }\end{array}$ & $\begin{array}{c}\text { Cores in } \\
\text { MZ13 } \\
\text { transect }\end{array}$ & $\begin{array}{c}\text { Mean } \chi_{\text {lf }} \\
\mathbf{( 1 0}^{-8} \mathbf{m}^{\mathbf{3}} \\
\left.\mathbf{k g}^{-1}\right)\end{array}$ & $\begin{array}{l}\text { Erosion } \\
\text { by } \mathbf{T H} \\
\text { model d doss } \\
\text { (cm) }\end{array}$ \\
\hline Summit & $13 \mathrm{~A}$ & 39.25 & -127.29 \\
\hline Shoulder & $13 \mathrm{~B}$ & 89.33 & -80.22 \\
\hline Backslope & $13 \mathrm{C}$ & 182.33 & 13.22 \\
& $13 \mathrm{D}$ & 96.66 & -74.17 \\
& $13 \mathrm{E}$ & 51 & -115.35 \\
& $13 \mathrm{~F}$ & 58 & -108.5 \\
& $13 \mathrm{G}$ & 135.75 & -41.09 \\
& $13 \mathrm{H}$ & 99.5 & -71.89 \\
& $13 \mathrm{I}$ & 106 & -71.24 \\
& $13 \mathrm{~J}$ & 124.33 & -53.08 \\
& $13 \mathrm{~K}$ & 110.66 & -66.75 \\
\hline Footslope & $13 \mathrm{~L}$ & 39 & -127.55 \\
\hline Toeslope & $13 \mathrm{M}$ & 12.66 & -156.35 \\
\hline
\end{tabular}

The results given in the above tables ( 2 and 3 ) show that lower magnetic susceptibilities are usually associated with higher soil losses, while higher susceptibilities to lower ones. Similar ascertainment has reported by Bouhlassa and Bouhsane (2019) in their study carried out in the Ait Azzouz watershed, located in the same region of the Mezguida watershed. According to the results given in table 2 , it is indicated that the core which subjects to a strong erosion is the $17 \mathrm{~L}$ core $(-154.9 \mathrm{~cm})$, this core is located at the end of the backslope position of the MZ17 transect. This slope position is the most inclined, and it represents the position of an intense erosion in the forested transect. In the MZ13 transect, soil loss is strong in the $13 \mathrm{M}$ core $(-156.35 \mathrm{~cm})$ which is located in the toeslope position of the MZ13 transect, this position is easily affected by erosion (Table 3). The soil loss in the cultivated transect in the summit is higher compared to those estimated in the same slope position in the forested transect; this is explained by the importance of the dense vegetation in the upperslope in the forested land favouring the soil stability and protection against erosion. However, the soil loss is higher in the backslope in the MZ17 comparing to those obtained in the same position in the cultivated transect.

Using the T-H model, Bouhlassa and Bouhsane (2019) have obtained higher soil losses in different soil profiles selected in cultivated and pastures lands. Their results confirm the impact of tillage on erosion in soils sampled in cultivated and pastures land on schist and marl substrates. In this study, the erosion is favoured in all the soils sampled along cultivated and forested transects at different slope positions. The Mezguida watershed has suffered from severe erosion; especially due to its alterable lithology and the dominance of cultivated lands.

\subsection{Determination of RUSLE factors and the estimation of soil loss by RUSLE in the Mezguida watershed}

\subsubsection{Erodibility factor $(K)$}

The erodibility factor map is obtained from the soil type map of the study area. Figure 5 shows that the $\mathrm{K}$ values varied between 0.2 and 0.44 showing the fragility of the soils of the MZ watershed, and its susceptibility to erosion. Indeed, the average erodibility class $\left(0.2-0.3 \mathrm{t}\right.$ ha $\left.\mathrm{h} \mathrm{MJ}^{-1} \mathrm{ha}^{-1} \mathrm{~mm}^{-1}\right)$ represents almost $69.3 \%$ of the surface of the watershed. The strong erodibility class $\left(0.3-0.4 \mathrm{t}\right.$ ha $\left.\mathrm{h} \mathrm{MJ}^{-1} \mathrm{ha}^{-1} \mathrm{~mm}^{-1}\right)$ represents $32.034 \%$ of the total surface of the watershed, this class characterizes soils less evolved.

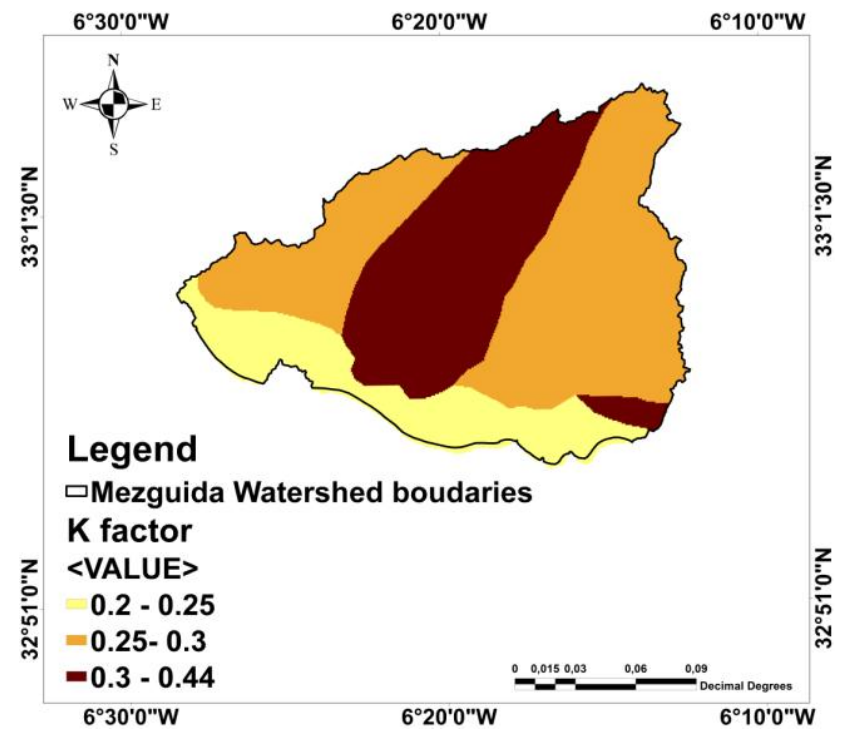

Figure 5. K factor map of Mezguida watershed

\subsubsection{Land use factor $(C)$}

In general, the level of soil protection in the Mezguida subbasin is quite low because most of its area is occupied by cropland. The $\mathrm{C}$ factor map is given in figure 6 . The low protection class covers a large area of the watershed (91\%) and 
only an area of $8.1 \%$ which is well protected. This is mainly due to the types of land use that exist in the region with a predominance of cultivated lands and the small surface of lands with dense vegetation.

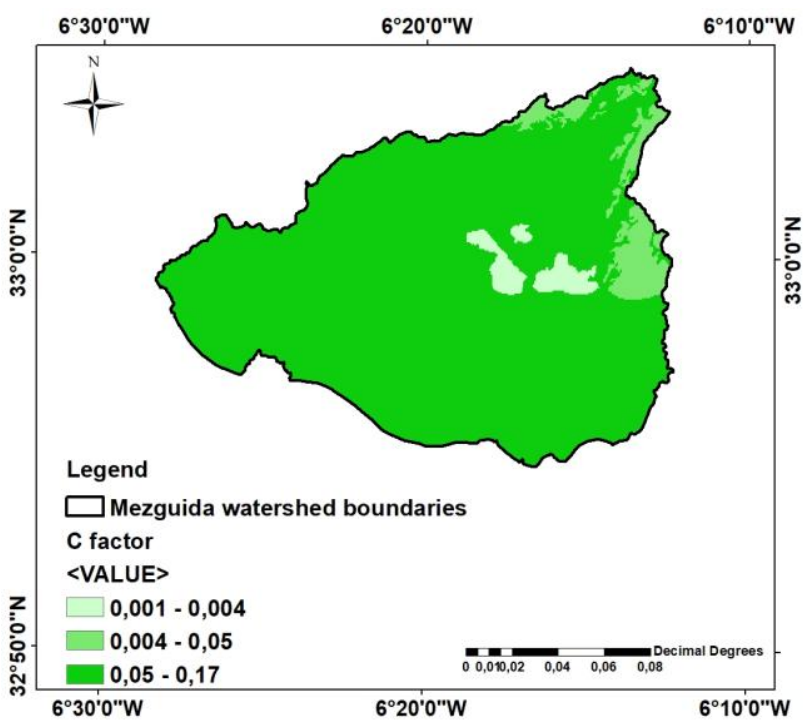

Figure 6. C factor map

\subsubsection{Topographic factor (LS)}

The topographic factor LS is classified with values ranging from 0.1 to 86.56 as it is shown in the spatial distribution map of the LS factor (Figure 7). This map shows that the highest values are generally located in the western parts of the basin. This is an indication of the importance of topography in the soil erosion process. The lower classes of LS which is between 0.1 and 18.74 represent $98.37 \%$ of the surface of the watershed, while the steep slopes occupy $1.61 \%$ of the surface of the basin. This confirms the effect of LS factor on erosion in the Mezguida watershed.

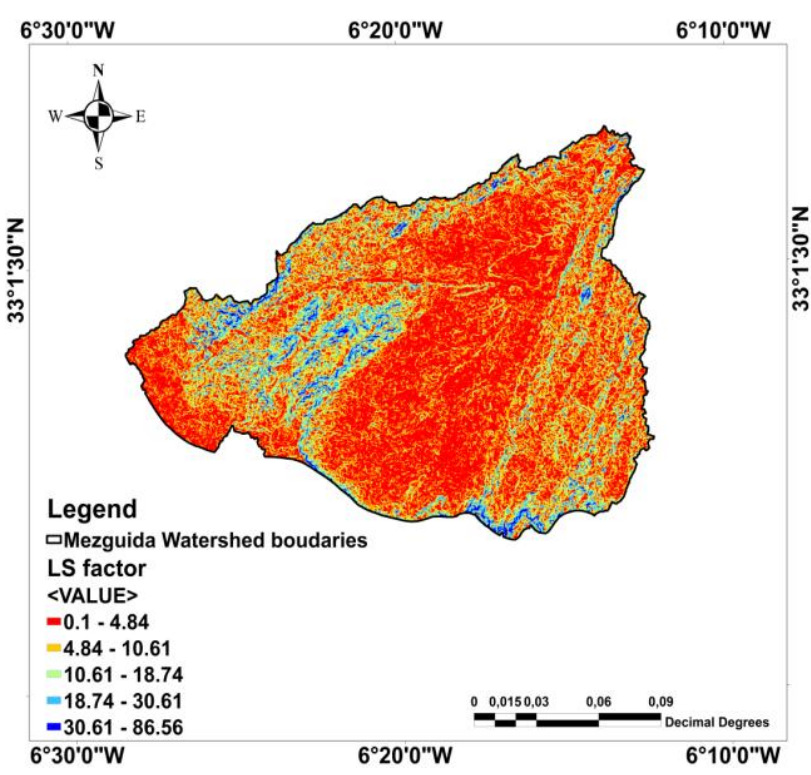

Figure 7. LS factor map

\subsubsection{Rainfall erosivity factor $(\mathbf{R})$}

The erosivity factor depends on climatic parameters such as precipitations which play an important role in erosion. The synthetic erosion map of MZ obtained from hydrographic station data shows that the $\mathrm{R}$ value is equal to $59 \mathrm{MJ} \mathrm{mm} \mathrm{ha}^{-1}$ $\mathrm{h}^{-1}$ year $^{-1}$ (Figure 8).

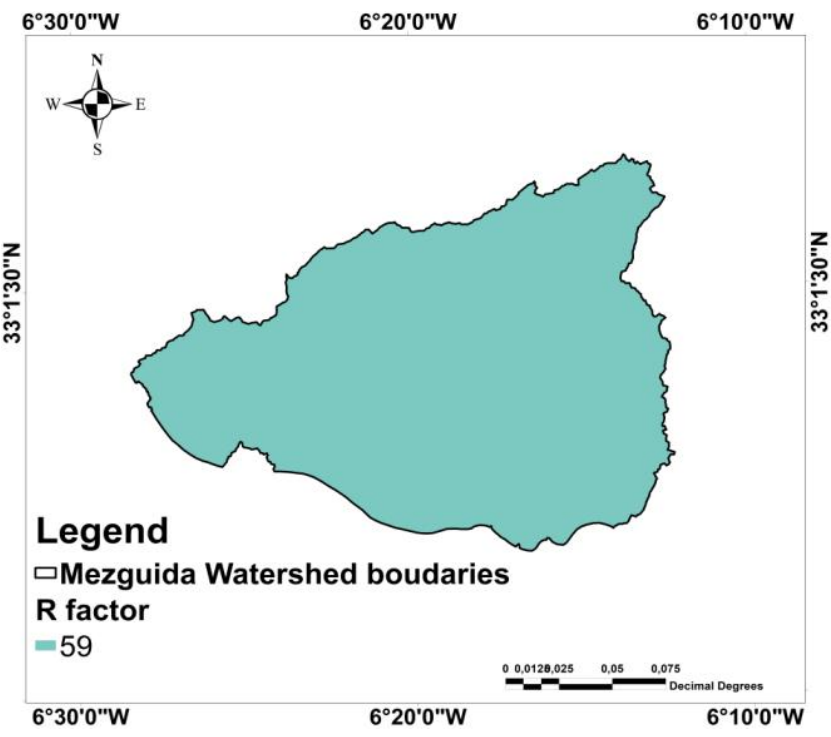

Figure 8. R factor map

\subsubsection{Support and conservation practices factor}

This factor depends on the anti-erosion practices carried out in the watershed. In the absence of these practices, we consider the $\mathrm{P}$ factor equal to 1 . So we do not take it into account in the RUSLE equation.

\subsubsection{Estimation of soil erosion in Mezguida watershed}

Land use is a factor that has a significant effect on erosion rates. Soil losses on bare or severely degraded lands are probably higher than those in areas with permanent vegetation, even on steep slopes. Soil loss differs from one area to another depending on erosion factors. There are several classifications of soil losses that have been proposed by researchers who have worked on erosion using RUSLE model in Morocco (Sadiki et al., 2004). The application of RUSLE model on the MZ watershed result in the soil erosion map (Figure 9). This figure shows an average soil loss of around $20.21 \mathrm{t} / \mathrm{ha} / \mathrm{yr}$, the maximum and minimum losses are respectively $329.67 \mathrm{t} / \mathrm{ha} / \mathrm{yr}$ and $0.0014 \mathrm{t} / \mathrm{ha} / \mathrm{yr}$, while the total soil losses in the watershed are about of $1241575.2 \mathrm{t} / \mathrm{ha} / \mathrm{yr}$. We have used the American classification which shows that soils can suffer losses of up to $7 \mathrm{t} / \mathrm{ha} / \mathrm{yr}$ on average and the erosion becomes serious threat if the losses are beyond $20 \mathrm{t} / \mathrm{ha} / \mathrm{yr}$. According to the classification adopted, we have classified the soil loss into five classes. The soil loss map shows that $30.2 \%$ of the surface of the basin has relatively very low losses, and it belongs to the class $0.0014-7 \mathrm{t} / \mathrm{ha} / \mathrm{yr} ; 35.38 \%$ of the area of the catchment belongs to the class of medium to high losses $7-20 \mathrm{t} / \mathrm{ha} / \mathrm{yr}$ indicating significant losses. While the rest of the watershed presents strong loss which belongs to the class $20-60 \mathrm{t} / \mathrm{ha} /$ yr, these classes occupy $28.3 \%$ of the surface of the watershed. 
A very strong loss $>60 \mathrm{t} / \mathrm{ha} / \mathrm{yr}$ occupy $6 \%$ of the watershed surface.

The results obtained by the RUSLE model confirm the presence and the visibility of erosive risk in the Mezguida watershed. The main factors contributed to soil erosion are the LS and C factors, because the LS factor classes in the MZ watershed with high values occupy large areas, and the watershed is dominated by cultivated lands.

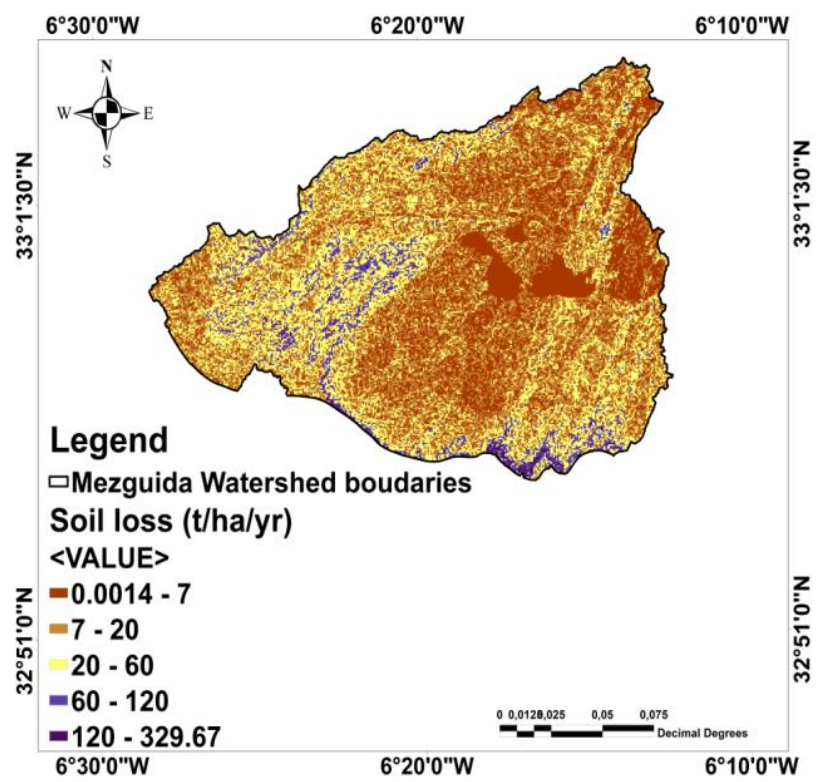

Figure 9. Soil loss map

\section{CONCLUSIONS}

Soil loss estimated in the soils collected in the Mezguida watershed using the tillage homogenization model $(\mathrm{T}-\mathrm{H})$ as improved is related to tillage practice and slope positions. Higher soil loss is occurred in the upper and lower slopes in cultivated lands, and in the middlsopes and lower slopes in the forested transect. The advantage of this model is to predict the total cumulative erosion in the last decades, it represents a method for the rapid quantification of soil loss.

The average soil loss in the Mezguida watershed obtained by the RUSLE model is about $20.21 \mathrm{t} / \mathrm{ha} / \mathrm{yr}$, the erosion map showed that strong loss occupies an important surface of the watershed. The main factors contributing to these higher erosion is the LS factor and the dominance of the cultivated lands.

The RUSLE model is considered effective for mapping and predicting soil losses through erosion in certain areas under given conditions of rainfall, soil erodibility, topography, and land use. It is not applicable for predicting the effects of eolian erosion or tillage displacement which may have modified the outcome of erosion. This approach has limitations in the assessment of erosion, and one of the more critical points is that it is intended for predicting soil movement, not soil removal from a field. Such error in one of the RUSLE factors will give an incorrect percentage of annual soil loss. These errors are in principle due to the inaccuracies of the components of each data item and to the limitations of the equations used to calculate the values of each RUSLE factor. As the RUSLE model applications are based on bibliographic data to obtain the values of each factor, the estimation of erosion by this method is still limited.

\section{ACKNOWLEDGMENTS}

The author would like to thank Pr. Saidati Bouhlassa for his contribution in the analysis of soils samples in the laboratory of Radiochemistry and Nuclear Chemistry of Faculty of science Rabat, and for his participation in the elaboration of the methodology and the manuscript.

\section{REFERENCES}

ArcMap. 2015. ArcGIS Desktop Release 10.3. Environmental Systems Research Institute.

Ayoubi, S., Ahmadi, M., Abdi, M.R., Afshar, F.A., 2012. Relationships of 137Cs inventory with magnetic measures of calcareous soils of hilly region in Iran. J. Environ. Radioactiv. 112, 45-51. https://doi.org/10.1016/j.jenvrad.2012.03.012.

Bartington Instruments. 2001. Bartington instruments: Magnetic susceptibility system [online]. Available at: http://www.bartington.com!ms2.htm [Accessed 28 August 2002].

Bouhlassa, S., Bouhsane, N., 2019. Assessment of areal water and tillage erosion using magnetic susceptibility: the approach and its application in Moroccan watershed. Environ Sci Pollut Res 26, 25452-25466. https://doi.org/10.1007/s11356-01905510-6.

Clark ML., 2015. Using GIS and the RUSLE Model to Create an Index of Potential Soil Erosion at the Large Basin Scale and Discussing the Implications for Water Planning and Land Management in Morocco. Master report in Global Policy Studies, University of Texas at Austin.

Dearing, J., 1994. Environmental magnetic susceptibility. Using the Bartington MS2 system. Kenilworth, Chi Publ.

Hassouni, K., Bouhlassa, S., 2006. Estimate of soil erosion on cultivated soils using $137 \mathrm{Cs}$ measurements and calibration models: A case study from Nakhla watershed, Morocco. Canadian Journal of Soil Science, 86(1), 7787. doi:10.4141/s04-052.

Jordanova, D., Jordanova, N., Atanasova, A., Ts, Tsacheva, Petrov, P., 2011. Soil tillage erosion estimated by using magnetism of soils - a case study from Bulgaria. Environmental Monitoring and Assessment 183, 381-394.

Jordanova, D., Jordanova, N., Petrov P., 2014. Pattern of cumulative soil erosion and redistribution pinpointed through magnetic signature of Chernozem soils. Catena 120: 46-56.

Landgraf, C., Royall, D., 2006. Spatial Patterns of Surface Soil Magnetism and Soil Redistribution Across a Fallow Field, Northern Alabama. Southeastern Geographer, 46(1), 1-22.

Renard, KG., Foster, GR., Weesies, GA., McCool, DK., Yoder, DC., 1997. Predicting soil erosion by water: a guide to conservation planning with the Revised Universal Soil Loss Equation (RUSLE). Agriculture Handbook No. 703, USDAARS. 
Royall, D., 2001. Use of mineral magnetic measurements to investigate soil erosion and sediment delivery in a small agricultural catchment in limestone terrain. Catena 46, 15-34.

Royall, D., 2004. Particle-size and analytical considerations in themineral-magnetic interpretation of soil loss from cultivated landscapes. Catena 57, 189-207.

Royall, D., 2007. A comparison of mineral-magnetic and distributed RUSLE modelling in the assessment of soil loss on a southeastern U.S. cropland. Catena 69, 170-180.

Sadiki, A., Faleh, A., Navas, A., Bouhlassa, S., 2009. Using magnetic susceptibility to assess soil degradation in the Eastern Rif, Morocco. Earth Surface Processes Landforms 34: 2057-2069.

Sadiki, A., Bouhlassa, S., Auajjar, J., Faleh, A., Macaire, J.J., 2004. Utilisation d'un SIG pour l'évaluation et la cartographie des risques d'érosion par l'Equation universelle des pertes en sol dans le Rif oriental (Maroc): cas du bassin versant de l'oued Boussouab. Bulletin de l'Institut Scientifique, Rabat, section Sciences de la Terre, n²6, 69-79.

United States Geological Survey's Earth Explorer (USGS) accessed in December 2019 via https://earthexplorer.usgs.gov/ Vegetation in Bouregreg River Basin. 2013. SIGMED. Accessed November 30, 2015.

Wijesundara, N. C., Abeysingha, N. S., Dissanayake, D. M. S. L. B., 2018. GIS-based soil loss estimation using RUSLE model: a case of Kirindi Oya river basin, Sri Lanka. Modeling Earth Systems and Environment 4(1): 251-262.

Wischmeier, W.H., Smith, D., 1978. Predicting rainfall erosion losses- a guide to conservation planning. U.S. Dept. of Agriculture.

Yu, Y., Zhang, K., Liu, L., 2017. Evaluation of the influence of cultivation period on soil redistribution in northeastern China using magnetic susceptibility. Soil Till. Res. 174, 14-23.

Yu, Y., Zhang, K., Liu, L., Ma, Q., Luo, J., 2019. Estimating long-term erosion and sedimentation rate on farmland using magnetic susceptibility in northeast China. Soil Tillage Research 187:41-49

Zhang, X.C.J., Zhang, G.H., Wei, X., 2015. How to make 137Cs erosion estimation more useful: An uncertainty perspective. Geoderma 186-194 239-240. 